\title{
Defining a training framework for clinicians in respiratory critical care
}

\author{
Antonio Artigas' ${ }^{1}$ Julie-Lyn Noël², Laurent Brochard³, Jamiu O. Busari4, \\ Dominic Dellweg ${ }^{5}$, Miguel Ferrer ${ }^{6}$, Jens Geiseler ${ }^{7}$, Anders Larsson ${ }^{8}$, \\ Stefano Nava9, Paolo Navalesi ${ }^{10}$, Stylianos Orfanos ${ }^{11}$, Paolo Palange ${ }^{12}$, \\ Paolo Pelosi ${ }^{13}$, Gernot Rohde ${ }^{14}$, Bernd Schoenhofer ${ }^{15}$, \\ Theodoros Vassilakopoulos ${ }^{16}$ and Anita K. Simonds ${ }^{17}$
}

Affiliations: ${ }^{1}$ Critical Care Center, CIBER Enfermedades Respiratorias, Sabadell Hospital, Corporació Sanitaria Universitaria Parc Tauli, Autonomous University of Barcelona, Barcelona, Spain. ${ }^{2}$ European Respiratory Society, Lausanne, Switzerland. ${ }^{3}$ Hopital Cantonal Universitaire de Genève, Geneva, Switzerland. ${ }^{4}$ Medical Residency Program, Department of Pediatrics, Atrium Medical Center, Heerlen, and Department of Educational, Development and Research, Faculty of Health. Medicine and Life Sciences, University of Maastricht, Maastricht, The Netherlands. ${ }^{5}$ Respiratory and Critical Care Medicine, Kloster Grafschaft, Schmallenberg, Germany. ${ }^{6}$ Servei de Pneumologia, Hospital Clinic, Villarroel, Spain. ${ }^{7}$ Chefarzt Klinik für Intensivmedizin und Langzeitbeatmung, Asklepios Fachkliniken München-Gauting, Gauting, Germany. ${ }^{8}$ Hedenstierna Laboratory, Uppsala University, Uppsala, Sweden. ${ }^{9}$ Respiratory and Critical Care, Sant' Orsola Malpighi Hospital, Bologna, Italy. ${ }^{10}$ Università del Piemonte Orientale "A. Avogadro", Dipartimento di Medicina Traslazionale, Novara, and SC Anestesia e Rianimazione, Ospedale Sant'Andrea (ASL VC), Vercelli, Italy. ${ }^{11}$ 2nd Dept of Critical Care, University of Athens Medical School, Attikon Hospital, Athens, Greece. ${ }^{12}$ Dipartimento Medicina Clinica, University La Sapienza, Rome, Italy. ${ }^{13}$ Dept of Surgical Sciences and Integrated Diagnostics, IRCCS AOU San Martino - IST, University of Genoa, Genoa, Italy. ${ }^{14}$ Dept of Respiratory Medicine Maastricht University Medical Center, Maastricht, The Netherlands. ${ }^{15}$ Dept of Pulmonary and Intensive Care Medicine, Klinikum Region Hannover, Krankenhaus Oststadt-Heidehaus, Hannover, Germany. ${ }^{16} 1$ st Dept of Pulmonary and Critical Care Medicine, University of Athens Medical School, Evangelismos Hospital, Athens, Greece. ${ }^{17}$ Academic Unit of Sleep and Breathing, Royal Brompton and Harefield NHS Foundation Trust, London, UK.

Correspondence: Antonio Artigas, Parc Tauli 1, Sabadell, 08208 Barcelona, Spain. E-mail: aartigas@atauli.cat

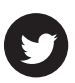

@ERSpublications

Defining a training framework for clinicians in respiratory critical care http://ow.ly/yExWj

As intensive care medicine (ICM) advances through technological developments, diagnostics and therapeutics, there are increasing demands on resources and healthcare budgets.

For these reasons, there is a need to create adequate legal and administrative structures. There is also an increasing requirement for qualified specialised personnel and an internationally recognised high-standard training programme [1]. This is especially relevant considering the multidisciplinary nature of ICM.

Bearing these developments in mind, a way to progress ICM would be to involve, among other specialties, more respiratory physicians, who can be significant care providers for critically ill respiratory patients [2].

Received: June 102014 | Accepted: June 122014

Conflict of interest: Disclosures can be found alongside the online version of this article at erj.ersjournals.com J-L Noël is an employee of the European Respiratory Society.

This editorial is a summary of the Respiratory Critical Care HERMES: European curriculum recommendations published in the March 2014 issue of Breathe.

Copyright @ERS 2014 
Furthermore, respiratory intermediate care units providing non-invasive monitoring and non-invasive ventilation allow for a more efficient and cost-effective management of respiratory failure patients without decreasing the quality of care or adversely affecting outcome [3,4]. Additionally, the development of weaning centres and long-term care facilities, including home ventilation, provide important economic advantages that decrease the burden on regular intensive care units (ICUs) by reducing admissions and facilitating discharge to step-down areas [1]. As a result, the respiratory physician with specialist critical care training can provide advantages to patients in these critical care settings [2].

Historically in Europe, respiratory physicians have not usually been in the forefront of assuming the care of the critically ill respiratory patient compared with other countries such as the USA [5]. However, growing interest in Europe in the role of the respiratory physician is manifested by joint consensus papers and employment of respiratory physicians in ICUs [6].

To facilitate this movement, the Respiratory Intensive Care Assembly of the European Respiratory Society (ERS) and the ERS Education Committee supported the creation of a Respiratory Critical Care HERMES (Harmonised Education in Respiratory Medicine for European Specialists) Task Force. This multidisciplinary team was composed of members from a wide range of relevant professional and educational backgrounds including respiratory medicine, critical care, anaesthesiology and internal medicine, and was supported by ERS Education staff.

The ultimate aim of the Respiratory Critical Care HERMES Task Force is to ensure that the best quality of care is delivered through harmonised educational standards in the context of these evolving medical and economic demands. It is noteworthy however that in Europe there is the challenge of differing critical care delivery, training infrastructures and certification standards across the different countries.

In order to support the role of the respiratory physician, the Task Force will contribute harmonised educational standards and a training framework in respiratory critical care. These educational standards for training and certification will be consensus based and will follow the methodology of the ERS global HERMES initiative established in 2005. Other respiratory specialty areas, such as adult respiratory medicine, paediatric respiratory medicine, spirometry, respiratory sleep medicine, thoracic oncology and respiratory physiotherapy follow the same development strategy with four key phases: 1) syllabus; 2) curriculum; 3) European assessments and certification; and 4) training centre and training network accreditation [7-11].

In 2012, the Respiratory Critical Care HERMES Task Force published a European syllabus for training in respiratory critical care medicine [12] and, very recently, the Task Force published European curriculum

TABLE 1 Curriculum modules of the Respiratory Critical Care syllabus

\section{Curriculum Modules}

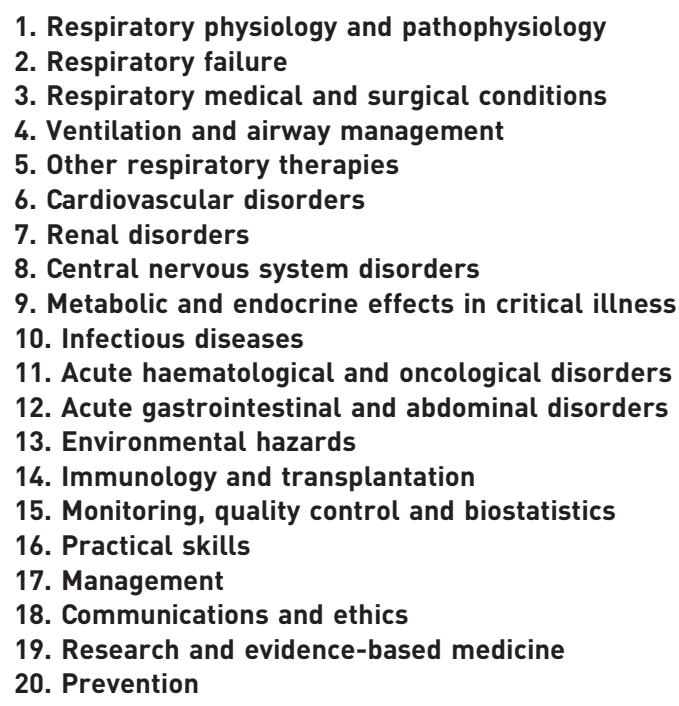




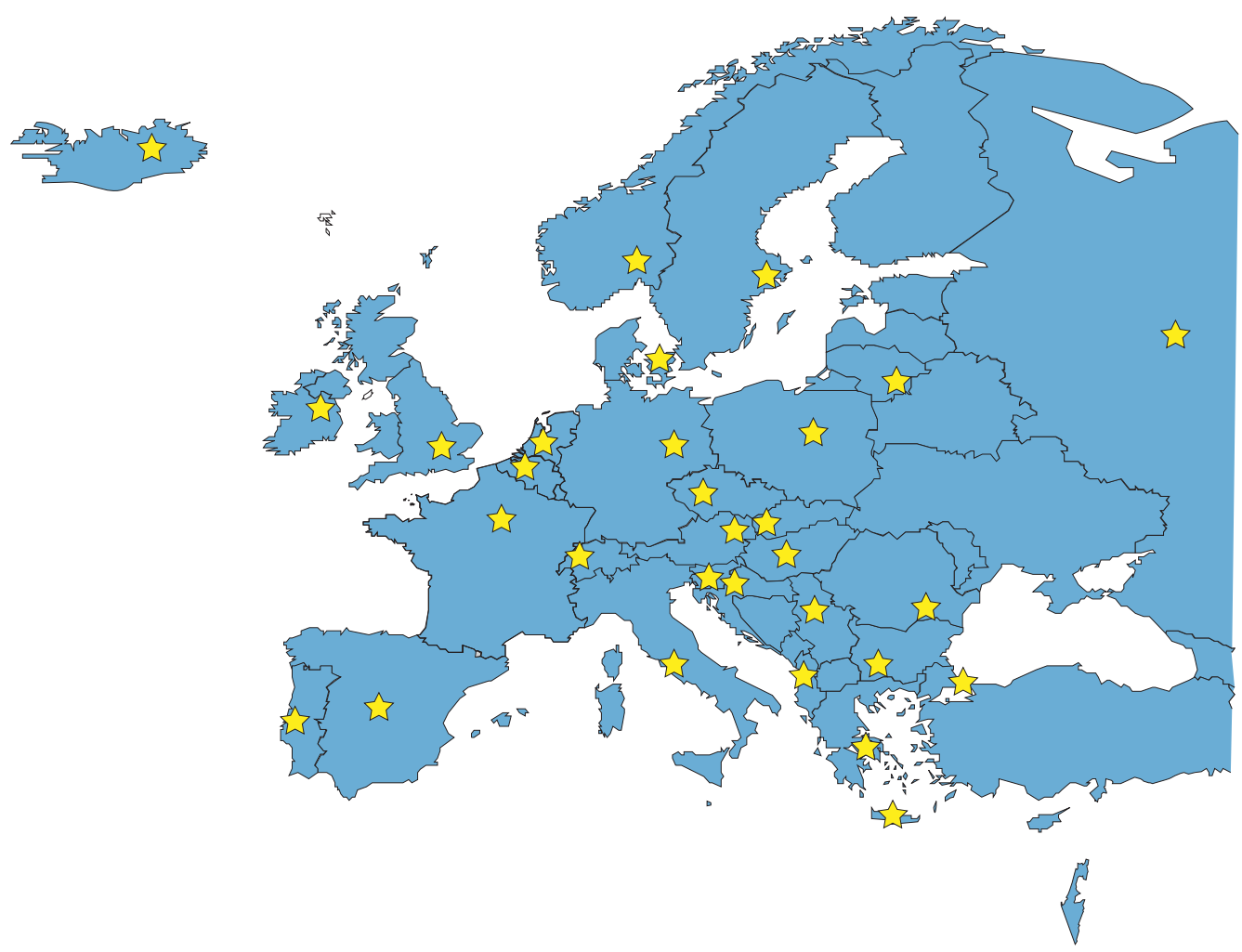

FIGURE 1 European representation of respiratory critical care HERMES participants. Includes: Albania, Austria, Belgium, Bulgaria, Croatia, Cyprus, Czech Republic, Denmark, France, Germany, Greece, Hungary, Iceland, Ireland, Italy, Lithuania, Netherlands, Norway, Poland, Portugal, Romania, Russian Federation, Serbia, Slovakia, Slovenia, Spain, Sweden, Switzerland, Turkey, UK.

recommendations in respiratory critical care [13]. The curriculum presented attempts to put the 2012 syllabus into operation and includes consideration of educational processes, mainly teaching, learning and assessment.

\section{Curriculum development}

The approach, methods and processes used were according to the global HERMES initiative and were adapted to the needs of a training programme in respiratory critical care [14, 15]. The Task Force formulated 20 curriculum modules based on the syllabus (table 1). National respondents, who were selected through the Forum of European Societies, were consulted and contributed to the content of the curriculum. Together with the Task Force members, they constitute the expert panel that validated actual practices in their respective countries (figure 1).

\section{European training concept}

The educational requirements that need to be met by the training programme are expressed in the European training concept as agreed by the Task Force participants at the outset. It should be stressed that the curriculum will define competencies for adult respiratory physicians who are not directly involved in multidisciplinary intensive care medicine but who will deliver only respiratory critical care. This can be regarded as a training framework in respiratory critical care medicine. Respiratory critical care medicine is regarded as an additional qualification open to doctors from other specialties in addition to adult respiratory medicine. It has been recognised that programmes, such as CoBaTriCE (Competency Based Training programme in Intensive Care Medicine for Europe), provide comprehensive training for intensive care physicians specialising across the range of intensive care subjects in general medical and surgical ICUs, in contrast to the specific area of respiratory critical care as described by this HERMES project $[16,17]$.

Each curriculum includes elements that articulate the expected learning outcomes in the training framework. This includes the following: 1) general theme/objective; 2) syllabus item; 3) learning outcomes, 


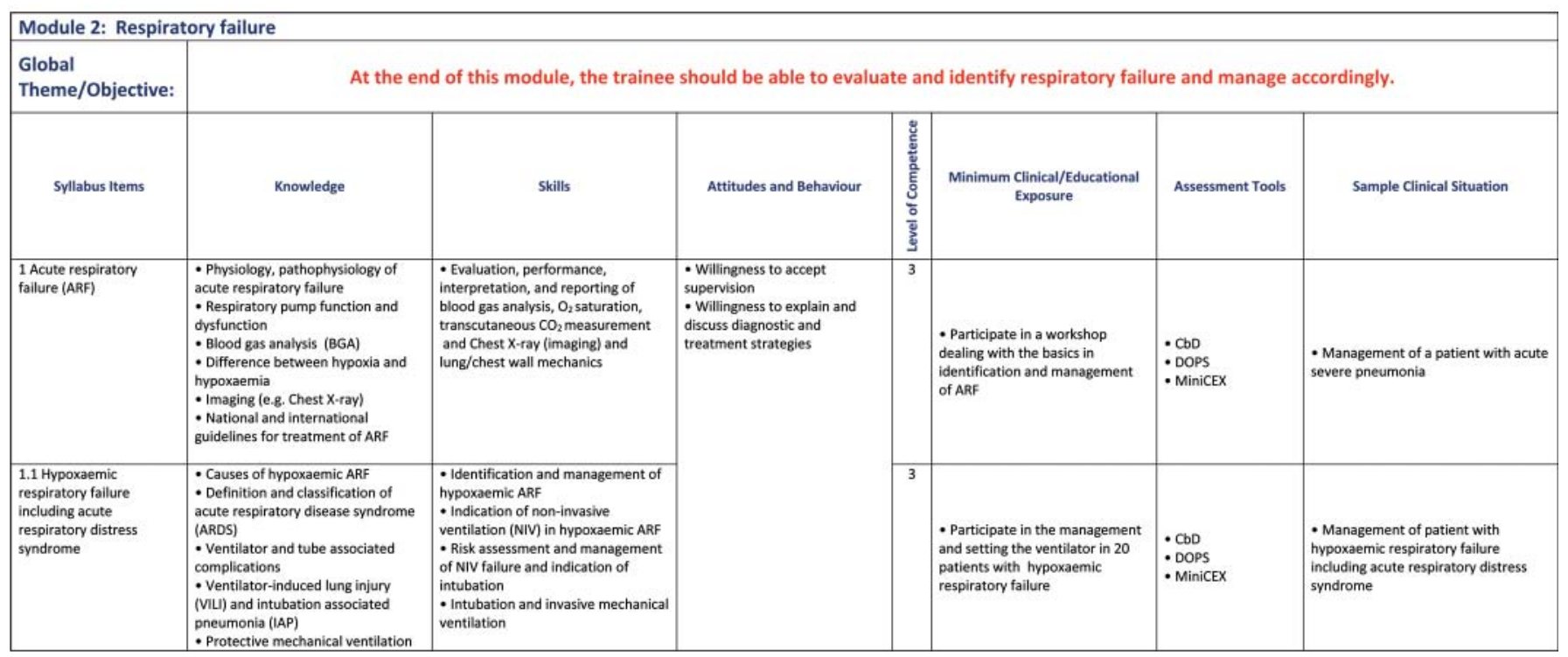

FIGURE 2 An example of a curriculum module.

such as knowledge, skills and attitudes and behaviour; 4) level of competence; 5) minimum clinical/ educational exposure; 6) recommended assessment methods; and 7) a sample clinical situation an example of which is elaborated at the introduction (figure 2). The complete 20 modules can be accessed online (www.ers-education.org/Media/Media.aspx?idMedia=236215).

The curriculum modules were completed by all participants in a mix of workshops, facilitated group discussions, Delphi-method consultations and plenary sessions.

These modules are designed to provide a concise, straightforward and user-friendly framework for training in respiratory critical care. The curriculum modules set out the integration of the defined learning outcomes and serve as a guide to the educational experience and opportunities in respiratory critical care.

\section{Assessment methods}

Simulation was recommended as an assessment tool in many instances such as for noninvasive and invasive mechanical ventilation, extracorporeal membrane oxygenation, airway maintenance, shock syndromes, pulmonary oedema, vasoactive and inotropic therapy, haemodynamic effects, drug dosing in renal failure and triage. It is the intention of the Critical Care Task Force to integrate simulator systems into respiratory critical care training. Examples and recommendations on how to integrate simulator systems exist and will be a further direction that can be taken [18].

\section{Strategies for implementation}

Throughout the curriculum development, great care was taken to ensure transparency of the process as well as to ensure that input was obtained from all involved in order to increase acceptability and applicability of the end product, i.e. curriculum recommendations and its framework.

According to an additional survey sent to all national respondents during syllabus development in September 2010, it was found that respiratory critical care medicine is taught as a subspecialty of pulmonology or respiratory medicine, and not a specialty of its own. Training periods vary between 3 months and 1 year [12]. In Cyprus, a syllabus based on the relevant sections of the CoBaTriCE framework is used [17]. Doctors in some countries, such as Iceland, often travel to the USA or other countries to gain respiratory critical care qualifications because these are officially recognised in their country [19].

The curriculum therefore defines specific competencies and provides a usable framework in the training of clinicians in respiratory critical care and aspires to set the stage for consolidation of an additional qualification and competence in respiratory critical care medicine. We hope that it is a starting point and a useful guide for countries to foster educational development activities in respiratory critical care. It is also 
intended that the participants of the exercise, i.e. the Task Force members and national respondents, will be able to propose educational development activities in their respective countries by approaching their national authorities.

\section{Conclusion}

In summary, the European curriculum recommendations for training in respiratory critical care medicine mark a new milestone in the Respiratory Critical Care HERMES initiative serving as the groundwork for collaborative interactions with other Societies involved in ICM. In this setting, the ERS can hopefully participate in a multi-society effort to improve and facilitate the homogenisation and standardisation of training across Europe, and the creation of uniform standards of care for critically ill respiratory disease patients $[20,21]$. The next step for the Task Force is to formulate an assessment framework using valid methods of competency assessment. Many other challenges remain, including faculty development, and the future task of developing training networks across Europe with accreditation activities.

\section{Acknowledgements}

The Task Force acknowledge the process expertise from the medical education advisor, Jamiu Busari (Dept of Educational Development and Research, University of Maastricht, Maastricht, the Netherlands) and ERS Headquarters office coordination by Julie-Lyn Noël (ERS Headquarters, Lausanne, Switzerland) in the formulation of the syllabus.

The following experts participated as national respondents: Bulgaria: D. Osmanliev, K. Kostov, V. Hodgev, O. Georgiev, D. Petkova, Y. Ivanov; Cyprus: T. Kyprianou, A.Rigas, A.Sergis; Czech Republic: V. Koblížek, J. Chlumský, P. Jakubec, L. Fila, L. Havel; France: J-D. Chiche, A. Rabbat, A. Cuvelier, T. Similowski, O. Sanchez, A. Demoule, C. Pison; Germany: M. Pfeifer, T. Welte; Greece: P. Argiropoulou; Hungary: É. Vizi, G. Böszörményi Nagy, P. Gordana, B. Igor, M. Suzana, M. Kornelija, J. Marko, M. Dubravka, P. Hrvoje; Iceland: G. Gudmundsson, Ó. Einarsson; Ireland: E. Maloney, R. Fahy, E. Moloney, M. Kennedy, A. O’Regan, E. Mulloy, M. Herzig; Italy E. Clini, N. Ambrosino; Lithuania: G. Kekstas, J.Sipylaite, S. Vosylius, A. Radziunas, K. Malakauskas, S. Miliauskas; Portugal: C. Barbara, J.C. Winck, J.Valença, P. Simão, J. Moita, J. Cardoso; Romania: R. Stoica, A. Macri, S. DumitracheRujinski, S.Dan, D. Boisteanu, M. Ciontu; Russia: S. Avdeev, V. Ridnov, A. Vanyushin; Serbia: I. Stankovic, L. Ristic, Z. Lazic, L. Bibic, B. Bulajic, M. Vukcevic Batranovic, L. Sagic, O. Ljiljana; Spain: A. Torres, G. González, L. Blanch, C. León, J. Mancebo, A. Esteban, J. Blanco, F. Baigorri, E. Fernández Mondéjar; Switzerland: J-C. Chevrolet, P. Jolliet, D. Tassaux; UK: J. Bion, A. Rhodes.

\section{References}

1 Respiratory intensive care. In: Gibson GJ, Loddenkemper R, Sibille Y, et al. eds. European Lung White Book. European Respiratory Society, Sheffield, 2013. pp. 358-361.

2 Evans T, Elliott MW, Ranieri M, et al. Pulmonary medicine and adult critical care medicine in Europe. Eur Respir J 2002; 19: 1202-1206.

3 Nava S, Confalonieri M, Rampulla C. Intermediate respiratory intensive care units in Europe: a European perspective. Thorax 1998; 53: 798-802.

Llinàs ES. Respiratory Intermediate Care Units. Arch Bronconeumol 2008; 44: 1-2.

Pneumatikos E. Pulmonology or Pulmonary and Critical Care Medicine. A dilemma for the future. Pneumon 2007; 20: 2 e.

6 Torres A, Ferrer M, Blanquer JB, et al. Intermediate respiratory intensive care units: definitions and characteristics. Arch Bronconeumol 2005; 41: 505-512.

7 Loddenkemper R, Séverin T, Haslam PL. European curriculum recommendations for training in adult respiratory medicine: crossing boundaries with HERMES. Eur Respir J 2008; 32: 538-540.

8 Gappa M, Noël JL, Séverin T, et al. European Curriculum Recommendations for Training in Paediatric Respiratory Medicine: one step further. Eur Respir J 2010; 36: 478-479.

9 Steenbruggen I, Mitchell S, Séverin T, et al. Harmonising spirometry education with HERMES: training a new generation of qualified spirometry practitioners across Europe. Eur Respir J 2011; 37: 479-481.

10 Gamarra F, Boffetta P, De Ruysscher D, et al. Thoracic Oncology HERMES syllabus: setting the basis for thoracic oncology training in Europe. Eur Respir J 2013; 42: 1183-1185.

11 Mitchell S, Pitta F, Troosters T. Standardised education and training for respiratory physiotherapists. Breathe 2013; 9: $171-174$

12 Artigas A, Vassilokopoulos T, Brochard L, et al. Respiratory Critical Care HERMES: a European core syllabus in respiratory critical care medicine. Breathe 2012; 8: 217-229.

13 Artigas A, Noël JL, Brochard L, et al. Respiratory Critical Care HERMES: European curriculum recommendations. Breathe 2014; 10: 15-22.

14 Loddenkemper R, Haslam PL, Séverin T, et al. European curriculum recommendations for training in adult respiratory medicine: 2nd report of the HERMES Task Force. Breathe 2008; 5: 80-93.

15 Gappa M, Noël JL, Séverin T, et al. Paediatric HERMES: European curriculum recommendations for Training in Paediatric Respiratory Medicine. Breathe 2010; 7: 72-79.

16 Artigas A, Pelosi P, et al. Respiratory critical care HERMES syllabus: defining competencies for respiratory doctors. Eur Respir J 2012; 39: 1294-1297.

17 European Society of Intensive Care Medicine, 2011. An international Competency Based Training programme in Intensive Care medicine-CoBaTrICE. www.cobatrice.org/Data/ModuleGestionDeContenu/PagesGenerees/en/02competencies/7.asp Date last accessed: 10 December 2013. 
Lighthall GK, Barr J. The Use of Clinical Simulation Systems to Train Critical Care Physicians. J Intensive Care Med 2007; 22: 257-269.

19 Halpern NA, Pastores SM, Oropello JM, et al. Critical care medicine in the United States: addressing the intensivist shortage and image of the specialty. Crit Care Med 2013; 41: 2754-2761.

20 Bion J Rothen HU, .Models for Intensive Care Training. A European Perspective. Am J Respir Crit Care Med 2014; 189: $256-262$.

21 Burchardi H. Specialty status for intensive care medicine? Critical Care 1999; 3: R53-R54. 